\title{
Dispelling Five Myths about E-books
}

Some considered 2000 the year of the e-book, and due to the dot-com bust, that could have been the format's highwater mark. However, the first quarter of 2004 saw the greatest number of e-book purchases ever with more than $\$ 3$ million in sales. A 2002 consumer survey found that 67 percent of respondents wanted to read e-books; 62 percent wanted access to e-books through a library. Unfortunately, the large amount of information written on e-books has begun to develop myths around their use, functionality, and cost. The author suggests that these myths may interfere with the role of libraries in helping to determine the future of the medium and access to it. Rather than fixate on the pros and cons of current versions of e-book technology, it is important for librarians to stay engaged and help clarify the role of digital documents in the modern library.

A 1though 2000 was unofficially proclaimed as the year of the electronic book, or e-book, due in part to the highly publicized release of a Stephen King short story exclusively in electronic format, the dot-com bust would derail a number of high-profile e-book endeavors. With far less fanfare, the e-book industry has been slowly recovering. In 2004, e-books represented the fastest-growing segment of the publishing industry. During the first quarter of that year, more than four hundred thousand e-books were sold, a 46 percent increase over the previous year's numbers. ${ }^{1}$ E-books continue to gain acceptance with some readers, although their place in history is still being determined-fad? great idea too soon? wrong approach at any time? The answers partly depend on the reader's perspective. The main focus of this article is the role of e-book technologies in libraries.

Libraries have always served as repositories of the written word, regardless of the particular medium used to store the words. From the ancient scrolls of Qumran to the hand-illuminated manuscripts of medieval Europe to the familiar typeset codices of today, the library's role has been to collect, organize, and share ideas via the written word.

In today's society, the written word is increasingly encountered in digital form. Writers use word processors; readers see words displayed; and researchers can scan countless collections without leaving the confines of the office. For self-proclaimed book lovers, the digital world is not necessarily an ideal one. Emotional reactions are common when one imagines a world without a favorite writing pen or the musty-smelling, yellowed pages of a treasured volume from youth.
One of the battle lines between the traditional bibliophile and the modern technologist is drawn over the concept of the e-book. Some see this digital form of written word as an evolutionary step beyond printed texts, which have been sometimes humorously dubbed tree-books.

Although a good deal of attention has been generated by the initial publicity regarding newer e-book technologies, the apparent failures of most of them has begun to establish myths around the concept. Abram points out that the relative success of e-books in niche areas (such as reference works) is in direct contrast with public opinion of those purchasing novels and popular literature through traditional vendors. ${ }^{2}$ Crawford paraphrases Lewis Carroll in describing this confusion: "When you cope with online content about e-books, you can believe six impossible things before breakfast." ${ }^{\prime \prime}$ Incidentally, this article will attempt to dispel a mere five of the myths about e-books.

The future of e-books and the critical role of libraries in this future are best served by uncovering these myths and seeking a balanced, reasoned view of their potential. A 2002 consumer survey on e-books found that 67 percent of respondents wanted to read an e-book, and 62 percent wanted that access to be from a library. ${ }^{4}$ Underlying this position is the assumption that the ideas represented by the written word are of paramount importance to both writers and readers. It is also assumed that libraries will continue their critical role in collecting, organizing, and sharing information.

\section{Myth 1-E-books Represent a New Idea That Has Failed}

Many libraries have invested in various forms of e-book delivery with mixed results. ${ }^{5}$ Sottong wisely warns of the premature adoption of e-book technology, which he dubs a false pretender as a replacement to printed texts. ${ }^{6}$ However, the last five years are but a small part of a longer history, and presumably, a still longer future

As is often the case with computer jargon, the term e-book has emerged and gained currency in a very short amount of time. However, the concept of providing written texts in an electronic format has existed for a long time, as demonstrated by Bush's description of the

James E. Gall (james.gall @ unco.edu) is Assistant Professor of Educational Technology at the University of Northern Colorado, Greeley. 
memex. ${ }^{7}$ The Gutenberg Project put theory into practice by converting traditional texts into digital files as early as $1971 .{ }^{8}$ Even if the $e$-book merely represents the latest incarnation of the concept, it does so tenuously.

Books in their present form have a history of hundreds of years, or thousands if their parchment and papyrus ancestors are included. This history is rich with successes and failures of technology. For example, Petroski presents an interesting historical examination of the problem of storing books when the one book-one desk model collapsed under the proliferation of available texts. ${ }^{9}$ Similarly, a determination on the success or failure of e-books, or digital texts, based upon a relatively short period of time, is fraught with difficulty. Rather, it is important to look at recent developments as merely a next step. The technology is clearly not ready for uncritical, widespread acceptance, but it is also deserving of more than a summary dismissal.

\section{Myth 2-E-books Are Easily Defined}

The term $e$-book means different things depending on the context. At the simplest, it refers to any primarily textual material that is stored digitally to be delivered via electronic display. One of the confusing aspects of defining ebooks is that in the digital world, information and the media used to store, transfer, and view it are loosely coupled. An e-book in digital form can be stored on CD-ROM or any number of other media and then passed on through computer networks or telephone lines. The device used to view an e-book could be a standard computer, a personal digital assistant (PDA), or an e-book reader (the dedicated piece of equipment on which an e-book can be read; confusingly, also referred to as an e-book). Technically, virtually any computing device with a display could be used as an e-book reader. From a practical point of view, our eyes might not tolerate reading great lengths of text on a wireless phone, and banks will not likely provide excerpts of Chaucer during ATM transactions.

Another important factor in defining e-books is the actual content. A conservative definition is that an e-book is an electronic copy or version of a printed text. This appears to be the predominant view of publishers. Purists often maintain that a true e-book is one that is specifically written for that format and not available in traditional printed form. ${ }^{10}$ This was one of the categories of the shortlived (2000-2002) Frankfurt E-book Awards. Of course, the multitude of textual materials that could be delivered via the technology exceeds these definitions. Magazines, primary-source documents, online commentaries and reviews, and transcripts of audio or video presentations are just a short list of nonbook materials that are finding their way into e-book formats. One can note with some sense of irony that the technology behind the Web was originally designed as a way for scientists to disseminate research reports. ${ }^{11}$ Despite the Web's popularity, reading research reports makes up an exceedingly small percentage of its use today.

Although there is a continuing effort to reach a common standard for e-books (see www.openebook.org/), the current marketplace contains numerous noncompatible formats. This noncompatibility is the result of both design and competitive tradeoffs. In the case of the former, there is a distinct philosophical difference between formats that attempt to retain the original look and navigation of the printed page (such as Adobe's popular PDF files) versus those that retain the text's structure but allow variability in its presentation (as best exemplified by the free-flowing nature of texts presented as HTML pages). This difference can also be seen in the functionality built around the format. Traditional systems provide readers with familiar book characteristics such as a table of contents, bookmarks, and margin notes, a view that could be named bibliocentric. The alternative is one that takes more advantage of the new medium and could be labeled technocentric, and can most easily be seen in the extensive use of hyperlinking. ${ }^{12}$ The simplest use of hyperlinking provides an easy form of annotating texts and presenting related texts. On the other extreme, hyperlinks are used in the creation of nonlinear texts in which the followed links provide a unique context for building meaning on the part of the reader. ${ }^{13}$ It is interesting to note that a preliminary study of e-book features found that the most desirable features tended to reflect the functionality of traditional books and the least desirable features provided functionality not found there. ${ }^{14}$

Competitive tradeoffs are a critical issue at the current point of e-book development. The current profit models of publishing entities and copyright concerns of authors seem naturally opposed to e-book formats in which texts were freely shared, duplicated, and distributed. For example, the Open Ebook Forum is the most prominent organization devoted to the development of standards for e-book technologies. In late 2004, their Web site listed seventy-six current members. Although the American Library Association is a member, it is one of only six members representing library-oriented organizations. In comparison, thirty-five members (or 46 percent) are publishing organizations, and thirteen (or 17 percent) are technology companies. ${ }^{15}$ The number of traditional publishers versus technology companies on this list may suggest that a bibliocentric view of ebooks would be more favored. This also appears to confirm one media prediction that traditional publishers would continue to dominate efforts with this new medium. ${ }^{16}$ However, the limited representation of libraries in this endeavor is troubling (despite the disclaimer of using an admittedly rough metric for measuring impact). It is clear that many industry formats attempt to limit the ability to 
distribute materials by keying files so that they may only be viewed on one device or a specific installed version of the reader software. This creates technological problems for entities like libraries that attempt to provide access to information for various parties. The concept of fair use of copyrighted materials has to be reexamined under an entirely new set of assumptions. Another irony is that the availability of free, public-domain materials in e-book format can be viewed as negative by the publishing industry. After investing considerable time and effort in developing e-book technology, publishers would prefer that users continue purchasing new e-book material rather than spend time reading the vast library of free historical material.

Many of these content issues are currently being played out in courts and the marketplace, particularly with regard to digital music and video. ${ }^{17}$ Although one can humorously imagine the so-called problems associated with a population obsessed with downloading and reading great literature, the precedents set by these popular media will have a direct impact on the future of digital texts. Despite the labor required to scan or key entire print books into digital formats, there have been some reports of this type of piracy. ${ }^{18}$ Other models for the dissemination of digital intellectual property that are not determined by traditional material concerns of supply and demand will continually be attempted. For example, Nelson predicted a hypertext-publishing scheme in which all material was available, but royalties were distributed according to actual access by end users. ${ }^{19}$ Theoretically, such a system would provide a perfect balance between access and profitability. In Nelson's words "Nothing will ever be misquoted or out of context, since the user can inquire as to the origins and native form of any quotation or other inclusion. Royalties will be automatically paid by a user whenever he or she draws out a byte from a published document." ${ }^{20}$

\section{Myth 3-E-books and Printed Books Are Competing Media}

Many, if not most, published articles regarding e-books follow classic plot construction; the writer must present a protagonist and an antagonist. Bibliophiles place the printed page as the hero and the e-book as the potential bane of civilization. Proulx, one such author, was quoted as saying, "Nobody is going to sit down and read a novel on a twitchy little screen-ever." ${ }^{21}$ Technologists cast the e-book as the electronic savior of text, replacing the tired tradition of the printed word in the same way the printed word replaced oral traditions. Hawkins quotes an author who claims that e-books are "a meteor striking the scholarly publication world." His slightly more restrained view was that e-books had the potential "to be the most far-reaching change since
Gutenberg's invention."22 Grant places this metaphorical battle at the forefront by titling an article "E-books: Friend or Foe?" 23 Before deciding which side to take, consider whether this clash of media is an appropriate metaphor.

This author has introduced samples of current ebook technology in graduate classes he has taught. When presented with the technology as part of the coursework, students quickly declare their allegiances. Bibliophiles most often suggest that the technology will never replace the love of curling up with a good book. The technologists will ask how many pages can be stored in the device and then fantasize about the types of libraries they can carry and the various venues for reading that they will explore. However, after a few weeks in using the devices, both groups tend to move to a middle ground of practical use. At that point, the discussion turns to what materials are best left on the printed page (usually described as pleasure reading) and what would be useful in e-book format (reference works, course catalogs, how-to manuals). Other instructors have reported similar patterns of use. ${ }^{24}$

At this point, the observation is largely anecdotal, but it does call into question the perceived need for a decisive referendum on the value of e-books. The issue is not whether e-books will replace the printed word. The concern of librarians and others involved in the infrastructure of the book should be on developing the proper role for e-books in a broader culture of information. Unless this approach is taken, the true goal of libraries-disseminating information to the public-will suffer. The gap between bibiliophile and technologist approaches can already be seen in the materials available in e-book format. The publishing industry in general treats the e-book as just another format, releasing the same titles in hardcover, book-on-tape, and e-book at the same time. On the opposite end of the spectrum, technologists have adopted various e-book formats for creating and transferring numerous reference documents. Given their preferences, it is easy to find e-book references on UNIX, HTML coding, and the like, but there is a scarcity of materials in philosophy, history, and the arts.

Librarians seem the most appropriate group for developing shared understanding. Publishers and e-book hardware and software manufacturers need to be concerned with the bottom line. Libraries, by design, are concerned with the preservation of information and its continued dissemination long after the need to sell a particular book has passed. The hobby of creating and transferring texts to digital form is idiosyncratic and unorganized when viewed from the highest levels. Libraries not only contain expertise in all areas of human endeavor, but also have strategies for categorizing and maintaining information in productive ways. In short, libraries are the best line of defense for maintaining the value of the printed page and promoting the value of digital texts. 


\section{Myth 4-E-books Are Expensive}

A common complaint about e-books is that they are expensive. On the surface, this seems clear. Dedicated ebook readers seemed to bottom out at around $\$ 300$, and a new bestseller in e-book format is priced about the same as the hardcover edition. Add the immediate and longterm costs of rechargeable batteries and the electricity needed to power them, and the economic case against the e-book appears closed.

What if we turn the same critical eye to the printed page? The manufacture and distribution of printed texts is highly developed and astounding. When Gutenberg succeeded in putting the Christian Bible in the hands of the moneyed public, he surely could not have comprehended the billions of copies that would eventually be distributed. Even with the wealth of printed material at hand, one must still consider the high cost of the system. The law of supply and demand rules books as a tangible product. The most profitable books are those that will reach the most readers. Specialized texts have limited audiences and, therefore, will usually be priced higher. This produces problems for both groups. Popular texts must be printed in high quantities and delivered to various outlets. Unfortunately, the printed page does have maintenance costs. Sellen and Harper point out that the actual printing cost is insignificant compared with the cost of dealing with documents after printing. They cite one study that indicated that United States businesses spend about $\$ 1$ billion per year designing and printing forms, but spend an additional \$25 to \$35 billion filing, storing, and retrieving them. ${ }^{25}$ Books are no different; as any librarian knows, it costs money to maintain a collection and protect texts from the environment and the effects of age. In the retail arena, the competition is fiercer. Books that do not sell are removed in favor of those that do. It is estimated that 10 percent of texts printed each year are turned to pulp, although, fortunately, many are recycled..$^{26}$ The $\mathrm{BBC}$ reported that more than two million former romance novels were used in the construction of a new tollway. ${ }^{27}$ With more specialized texts, the problem is not wealth, but scarcity. If a text is not profitable, it will probably become out of print. This is often synonymous with inaccessible. From the publisher's perspective, it is only cost-effective to commit to a printing when the demand is high enough. A library is a good source of outof-print texts, provided that it has been funded appropriately to acquire and maintain the particular works that are needed.

E-books are not a panacea. Other innovations, such as on-demand publishing, may be part of the answer in solving the economic issues regarding collections. However, e-books can help alleviate some of these issues. E-books are easily copied and distributed, which is a boon to the researcher and information consumer. In many cases, the goal is the access to information, not the possession of a book. It could also benefit the author and publisher if appropriate reimbursement systems are put into place. As previously described, Nelson originally envisioned his online hypertext system, Xanadu, with a mechanism for royalties based on access-a supply-anddemand system for ideas, not materials. ${ }^{28}$ The systems used to manage access to digital materials continue to increase in complexity and have spawned a whole new business of Digital Rights Management (DRM).. ${ }^{29}$ Examples include Reciprocal (www.reciprocal.com), OverDrive (www.overdrive.com), and netLibrary (www.net library.com). Libraries are the specific target of netLibrary, which promotes an E-Books-on-Demand project that allows free access for short periods of time..$^{30}$ The creation of a standard Digital Object Identifier (DOI) for published materials may also help online publishers and entities like libraries manage their digital collections more easily. ${ }^{31}$ Online music systems, such as Apple's iTunes (www. itunes.com), strike a workable balance between quickand-easy access to music and a workable, economic model for reimbursing artists. E-books also have appeal for special audiences who already require assistive technologies for accessing print collections. ${ }^{32}$

Having discussed the hidden costs of printed texts, another important economic issue of e-books to examine is a current trend in usage. Despite the availability of dedicated e-book readers, the largest growth in e-book usage is surely in nondedicated devices. E-book-reading software is available for personal computers, laptops, and PDAs. According to one source, Microsoft had sold four million PocketPC e-book-enabled devices, and had two million downloads of the MS Reader for the personal computer; Palm had sold approximately 20 million ebook-enabled devices; and Adobe had more than 30 million Acrobat readers downloaded. ${ }^{33}$ These numbers alone indicate some 24 million reader-capable PDAs, and 32 million reader-capable PCs, for a total of 56 million devices. Although it is difficult to find data on actual use, one online bookseller reported some data on e-book use from an audience survey. ${ }^{34}$ Although 88 percent had purchased books online, only 16 percent had read an e-book (11 percent using a PC, 3 percent on a handheld device, and 2 percent on both). It is presumed that in most cases this equipment was purchased for other reasons, with ebook reading being a secondary function. As such, it would be unfair to include the full cost of this equipment in any calculation of the cost of providing information in an e-book format. If so, the cost of providing artificial lighting in any building where reading takes place would need to be calculated as part of the cost of the printed page. The potential user base for the e-book rises as more computers and PDAs are sold, decreasing the need for special equipment. This does not mean that the dedicated 
e-book reader is obsolete. By most commercial accounts, the Apple Newton was a failure. Its bulky size and awkward interface were the subject of much ridicule. However, it did introduce the concept of the PDA. The success of the Palm line of products owes much to the proof of concept provided by the Newton. The makers of the portable Gameboy videogame system are repositioning it for multimedia digital-content delivery, and plan to pilot a flash-memory download system for various content types, including e-books. ${ }^{35}$ Innovative products such as e-paper are already developed in prototype form. ${ }^{36}$ They are likely to lead to another wave of dedicated e-book readers or provide e-book-reading potential embedded in other consumer applications.

\section{Myth 5-E-Books Are a Passing Fad}

It is trendy to list the failures of past media (such as radio, film, and television) in impacting education despite great initial promise. ${ }^{37}$ However, all those media are still with us after having found particular niches within our culture. If the e-book is viewed as just an alternative format, comparisons with past experiences of library collections containing videotapes, record albums, and such are not appropriate. ${ }^{38}$ However, if e-books are viewed as a tool or way to access information, the questions change. Instead of asking how digital formats will replace print collections, we can ask how will an e-book version extend the reach of our current collection or provide our readers with resources previously unavailable or unaffordable. When trying to locate a research article, one is generally not concerned with whether the local library has a loose copy, bound copy, microform, microfiche, or even has to resort to interlibrary loan. As long as the content is accessible and can be cited, it can be used. Electronic access to journal content is becoming more common. Perhaps dry journal articles do not conjure up the same romantic visions of exploring the stacks that may hinder greater acceptance of e-books.

A parallel can be drawn to the current work of filmrestoration experts. The medium of film has reached an age where some of the earliest influential works no longer exist or are in a condition of rapid deterioration. According to one film site, more than half of the films made before 1950 have already been lost due to decay of existing copies. ${ }^{39}$ The work of restoration involves finding what remains of a great work in various vaults and collections. Often, the only usable film is a second- or third-generation copy. From digitized copies, cleaning, color correction, and other painstaking work, a restored and-it is hoped-complete work emerges. Ironically, once this laborious process is completed, a near-extinct classic is suddenly available to millions in the form of a DVD disc at a local retailer.
What if the same attitude was taken with the world's collections of printed materials? Jantz has described potential impacts of e-book technology on academic libraries. ${ }^{40}$ Lareau conducted a study on using e-books to replace lost books at Kent State University, but found that limited availability and high costs did not make it feasible at the time. ${ }^{41}$ Project Gutenberg (www.gutenberg.net) and the Electronic Text Center at the University of Virginia (http:/ / etext.lib.virginia.edu) are two examples of scholars attempting to save and share book content in electronic forms, but more efforts are needed. Unfortunately, the shift to digital content has also contributed to the sheer volume of content available. Edwards has recently discussed issues in attempting to archive and preserve digital media. ${ }^{42}$ The Web may be suffering from a glut of information, but the content is highly skewed toward the new and technology oriented. In a few years, we may find that nontechnology-related endeavors are no longer represented in our information landscape.

\section{Conclusion}

The e-book industry is currently dominated by commercial-content providers, such as Franklin, and software companies, most notably Adobe, Palm, and Microsoft. Traditional print-based publishers have also maintained continued interest in the medium. It is assumed that these publishers had the capital to weather the ups and downs of the industry more so than new publishers dedicated solely to e-book delivery. Although the contributions and efforts of these organizations are needed, the future of e-book content should not be left to their largesse. When the Rocket e-book device was initially released, a small but loyal following of readers contributed thousands of titles to its online library. Some of these titles were self-published vanity projects or brief reference documents, but many were public-domain classics, painstakingly scanned or keyed in by readers wishing to share their favorite reads. When Gemstar purchased Rocket, the software's ability to create non-purchased content was curtailed and the online library of free titles dismantled. Apparently, both were viewed as limiting the profitability of the e-book vendor. However, Gemstar recently made notice of discontinuing their e-book reading devices, one would assume due to a lack of profitability. This can be seen as a cautionary tale for libraries, which often define success by number of volumes available and accessed rather than units sold. Committing to a technology that concurrently requires consumer success can be problematic.

Bibliophile and technologist alike must take responsibility for the future of our collective information resources. The bibliophile must ensure that all aspects of 
human knowledge and creativity are nurtured and allowed to survive in electronic forms. The technologist must ensure that accessibility and intellectual-property rights are addressed with every technological innovation. Parry provides three concrete suggestions for public libraries in response to new media demands: continue to acknowledge and respond to customer demands, revisit the library's mission statement for currency, and promote or accelerate shared agreements with other institutions to alleviate the high costs of accumulating resources ${ }^{43}$ The proper frame of mind for these activities is suggested by Levy:

We make a mistake, I believe, when we fixate on particular forms and technologies, taking them in and of themselves, to be the carriers of what we want to embrace or resist. . . . It isn't a question, it needn't be a question, of books or the Web, of letters or e-mail, of digital libraries or the bricks-and-mortar variety, of paper or digital technologies.... These modes of operation are only in conflict when we insist that one or the other is the only way to operate. ${ }^{44}$

In the early 1930s, Lomax dragged his primitive audio-recording equipment over the roads of the American South to capture the performances of numerous folk musicians. ${ }^{45}$ At the time, he certainly didn't imagine that at one point in history someone with a laptop computer sitting in a coffee shop with wireless access could download the performances of Robert Johnson from iTunes. However, without his efforts, those unique voices in our history would have been lost. It is hoped that the readers of the future will be thanking the library professionals of today for preserving our print collections and enabling their access digitally via our primitive, but evolving, e-book technologies.

\section{References}

1. Open E-book Forum, "Press Release: Record E-book Retail Sales Set in Q1 2004," June 4, 2004. Accessed Dec. 27, 2004, www.openebook.org.

2. Stephen Abram, "E-books: Rumors of Our Death Are Greatly Exaggerated," Information Outlook 8, no. 2 (2004): 14-16.

3. Walt Crawford, "The White Queen Strikes Again: An E-book Update," Econtent 25, no. 11 (2002): 46-47.

4. Harold Henke, "Consumer Survey on E-books." Accessed Dec. 27, 2004, www.openebook.org.

5. Sue Hutley, "Follow the E-book Road: E-books in Australian Public Libraries," APLIS 15, no. 1 (2002): 32-37; Andrew K. Pace, "E-books: Round Two," American Libraries 35, no. 8 (2004): 74-75; Michael Rogers, "Librarians, Publishers, and Vendors Revisit E-books," Library Journal 129, no. 7 (2004): 23-24.

6. Stephen Sottong, "E-book Technology: Waiting for the 'False Pretender,'” Information Technology and Libraries 20, no. 2 (2001): 72-80.
7. Vannevar Bush, "As We May Think," Atlantic Monthly 176, no. 1 (1945): 101-108.

8. Michael S. Hart, "History and Philosophy of Project Gutenberg." Accessed Dec. 27, 2004, www.gutenberg.net/ about.shtml.

9. Henry Petroski, The Book on the Bookshelf (New York: Vintage, 2000).

10. Steve Ditlea, "The Real E-books," Technology Review 103, no. 4 (2000): 70-73.

11. Tim Berners-Lee, Weaving the Web: The Original Design and Ultimate Destiny of the World Wide Web by Its Inventor (New York: HarperCollins, 1999).

12. James E. Gall and Annmari M. Duffy, "E-books in a College Course: A Case Study" (presented at the Association for Educational Communications and Technology Conference, Atlanta, Ga., Nov. 8-10, 2001).

13. George P. Landow, Hypertext 2.0: The Convergence of Contemporary Critical Theory and Technology (Baltimore, Md.: Johns Hopkins Univ. Pr., 1997).

14. Harold Henke, "Survey on Electronic Book Features." Accessed Dec. 27, 2004, www.openebook.org.

15. Open E-book Forum, "Press Release: Record E-book Retail Sales Set in Q1 2004."

16. Lori Enos, "Report: E-book Industry Set to Explode," E-commerce Times, 20 Dec. 2000. Accessed Dec. 27, 2004, www. ecommercetimes.com/story/6215.html.

17. Luis A. Ubinas, "The Answer to Video Piracy," McKinsey Quarterly no. 1. Accessed Accessed Dec. 27, 2004, www .mckinseyquarterly.com.

18. Mark Hoorebeek, "E-books, Libraries, and Peer-toPeer File-Sharing," Australian Library Journal 52, no. 2 (2003): 163-68.

19. Theodor H. Nelson, "Managing Immense Storage," Byte 13, no. 1 (1988): 225-38

20. Ibid., 238.

21. Jacob Weisberg, "The Way We Live Now: The Good Ebook," New York Times, 4 June 2000. Accessed Dec. 27, 2004, www.nytimes.com.

22. Donald T. Hawkins, "Electronic Books: A Major Publishing Revolution. Part 1: General Considerations and Issues," Online 24 , no. 4 (2000): 14-28.

23. Steve Grant, "E-books: Friend or Foe?" Book Report 21, no. 1 (2002): 50-54.

24. Lori Bell, "E-books Go to College," Library Journal 127, no. 8 (2002): 44-46.

25. Abigail J. Sellen and Richard H. Harper, The Myth of the Paperless Office (Cambridge, Mass.: MIT Pr., 2002).

26. Stephen Moss, "Pulped Fiction," Sydney Morning Herald, 29 Mar. 2002. Accessed Dec. 27, 2004, www.smh.com.au.

27. BBC News, "M6 Toll Built with Pulped Fiction," BBC News UK Edition, 18 Dec. 2003. Accessed Dec. 27, 2004, http:// news.bbc.co.uk

28. Nelson, "Managing Immense Storage."

29. Michael A. Looney and Mark Sheehan, "Digitizing Education: A Primer on E-books," Educause 36, no. 4 (2001): 38-46.

30. Brian Kenney, "netLibrary, EBSCO Explore New Models for E-books," Library Journal 128, no. 7 (2003).

31. Stephen H. Wildstrom, "A Library to End All Libraries," Business Week (July 23, 2001): 23. 
32. Terence Cavanaugh, "E-books and Accommodations: Is This the Future of Print Accommodation?" Teaching Exceptional Children 35, no. 2 (2002): 56-61.

33. Skip Pratt, "E-books and E-publishing: Ignore MS Reader and Palm OS at Your Own Peril," Knowledge Download, 2002. Accessed Dec. 27, 2004, www.knowledge-download.com/260802 -e-book-article.

34. Davina Witt, "Audience Profile and Demographics," Mar./Apr. 2003. Accessed Dec. 27, 2004, www.bookbrowse.com/ media/audience.cfm.

35. Geoff Daily, "Gameboy Advance: Not Just Playing with Games," Econtent 27, no. 5 (2004): 12-14.

36. Associated Press, "Flexible E-paper on its Way," Associated Press, 7 May 2003. Accessed Dec. 27, 2004, www.wired.com/news.

37. Richard Mayer, Multimedia Learning (Cambridge, UK: Cambridge University Press, 2000).

38. Sottong, "E-book Technology."

39. AMC, "Film Facts: Read About Lost Films." Accessed June
19, 2003, www.amctv.com/article?CID=1052.

40. Ronald Jantz, "E-books and New Library Service Models: An Analysis of the Impact of E-book Technology on Academic Libraries," Information Technology and Libraries 20, no. 2 (2001): $104-15$.

41. Susan Lareau, The Feasibility of the Use of E-books for Replacing Lost or Brittle Books in the Kent State University Library, 2001, ERIC, ED 459862. Accessed Dec. 27, 2004, http://searcheric.org.

42. Eli Edwards, "Ephemeral to Enduring: The Internet Archive and Its Role in Preserving Digital Media," Information Technology and Libraries 23, no. 1 (2004): 3-8.

43. Norm Parry, Format Proliferation in Public Libraries, 2002, ERIC, ED 470035,. Accessed Dec. 27, 2004, http://searcheric.org.

44. David M. Levy, Scrolling Forward: Making Sense of Documents in the Digital Age (New York: Arcade Pub., 2001).

45. About Alan Lomax. Accessed Dec. 27 2004, www.alan -lomax.com/about.html.
(President's column continued from page 2)

online." They have implemented several process improvements already and will complete their work by the 2005 ALA Annual Conference. This past fall, Michelle Frisque, LITA Web Manager, conducted a survey of our members about the LITA Web site. Michelle and the Web Coordinating Committee are already working on a new look and feel for the LITA Web site based on the survey comments, and the result promises to be phenomenal.

On top of all of the current activities, new vision statement, strategic planning, and the LITA Web site redesign, Mary Taylor and the LITA board worked with a graphic designer to develop a new LITA logo. After much deliberation, the new logo debuted at the 2004 LITA National Forum with great enthusiasm. Many members commented that the new logo expresses the "energy" of LITA and felt the change was terrific.

With your help, LITA had a very successful conference in Orlando. Although there were weather and transportation difficulties, the LITA programs and discussions were of the highest quality, as always. The program and preconference offerings for the upcoming Annual Conference in Chicago promise to be as strong as ever. Don't forget, LITA also offers Regional Institutes throughout the year. Check the LITA Web site to see if there's a Regional Institute scheduled in your area.
LITA held another successful National Forum in fall 2004 in St. Louis, "Ten Years of Connectivity: Libraries, the World Wide Web, and the Next Decade." The threeday educational event included excellent preconferences, general sessions, and more than thirty concurrent sessions. I want to thank the wonderful 2004 LITA National Forum Planning Committee, chaired by Diane Bisom, the presenters, and the LITA office staff who all made this event a great experience. The next LITA National Forum will be held at the San Jose Marriott, San Jose, California, September 29-October 2, 2005. The theme will be "The Ubiquitous Web: Personalization, Portability, and Online Collaboration." Thomas Dowling, chair, and the 2005 LITA National Forum Planning Committee are preparing another "must attend" event.

Next year marks LITA's fortieth anniversary. 2006 will be a year for LITA to celebrate our history, future, and our many accomplishments. We are fortunate to have Lynne Lysiak leading the Fortieth Anniversary Task Force activities. I know we all will enjoy the festivities.

I look forward to working with many of you as we continue to make LITA a wonderful and vibrant association. I encourage you to send me your comments and suggestions to further the goals, services, and activities of LITA.

\section{Index to Advertisers}

Art \& Tech

EBSCO
24

cover 2 covers $3-4$ 